\title{
A Good Samaritan inspired foundation for a fair health care system
}

\author{
Elmar H. Frangenberg
}

Published online: 17 June 2010

(C) The Author(s) 2010. This article is published with open access at Springerlink.com

\begin{abstract}
Distributive justice on the income and on the service aspects is the most vexing modern day problem for the creation and maintenance of an all inclusive health care system. A pervasive problem of all current schemes is the lack of effective cost control, which continues to result in increasing burdens for all public and private stakeholders. This proposal posits that the responsibility and financial obligation to achieve an ideal outcome of equal and affordable access and benefits for all citizens is misplaced. The Good Samaritan demonstrated basic ethical principles, which are revisited, elaborated and integrated into a new approach to health care. The participants are limited to individual contributors and beneficiaries and organized as a citizen carried, closed, independent, and self-sufficient selfgoverning cooperative for their own and the benefit of a minority of disadvantaged health care consumers. The government assumes oversight, provides arbitration, enforces democratic decision making, a scheme of progressive taxation, a separate and transparent accounting system, and a balance between income and reinvestment in health care. The results are a fair distribution of cost, its effective control, and increased individual motivation to take on responsibility for personal health as a private good and a sharpened focus towards community health. At the sociopolitical level the
\end{abstract}

\section{E. H. Frangenberg ( $\square)$}

Department of Neurology, University of Rochester School of Medicine and Dentistry, Rochester, NY, USA

e-mail: cfran@frontiernet.net

E. H. Frangenberg

CP Rochester, Rochester, NY, USA

E. H. Frangenberg

1099 Pinnacle Road, POB 374, Henrietta, NY 14467, USA government as well as employers are released from the inappropriate burden of catering to individual health.

Keywords Cost spiral in health care .

Beneficence as universal attitude .

Autonomy equals self-rule $\cdot$ Health care cooperative .

Health as private good $\cdot$ Built in cost control

\section{Problems of present health care insurance schemes}

All Western industrialized nations have developed health care systems as a prominent part of a social safety net for their citizens. From a socioeconomic viewpoint Denier (2008) comments on the phenomenon of inherent scarcity in health care and warns that a continually growing supply generates its own demand. Consequently health care spending has consistently increased per capita and as a percent of the gross domestic product over the past decades. The United States is the most notable outlier (Anderson et al. 2000; Kaiser Family Foundation 2009). Currently the customary funding streams in the form of insurance schemes, employer contributions and subsidies from general tax revenues are already severely strained in Western World societies. Total expenditures for health care range at close to ten percent of the Gross Domestic Product in the Netherlands, France, Switzerland and Germany and at a high of sixteen percent in the Unites States (Organization for Economic Cooperation and Development 2009). The balance sheet for the French health care system is negative (Lenain 2000). The Medicare Trust Fund, a universal health insurance scheme for those over 65 years in the United States is threatened with insolvency by 2019 (Boards of Trustees for Medicare 2009). 
Commonly cited forces which continually have been escalating the cost for maintenance of health care systems are technical advances in medical practice and biological research and an increasing longevity with growing disease burdens. If these tendencies are projected into the future, eventually all national resources could readily be spent to cater to individual health care needs and desires. This open ended, potentially bankrupting trend is the consequence of a presumed and occasionally proclaimed basic human right to health care (United Nations 1948). Such right is not fundamentally disputed. Instead this proposal claims that the responsibility for enforcement and practical fulfillment of a right to health care is misplaced. Beneficence and autonomy, historically expressed as charity, will be explored for their role in a new, modern day approach to ameliorate current problems.

\section{Social, philosophical and ethical considerations}

Arguments in favor of a right to health care have relied on a duty towards collective social protection and creating a fair opportunity. This view imposes an oppressive burden on society as provider of services for all its citizens and creates a permanent entitlement. In the perspective of this proposal the most undesirable side effect at the individual level is the promotion of a passive and expectant attitude towards health and its potential impairment. Even a scaled down version of a 'decent minimum of health care' faces the controversial challenge of determining its dimension, since individual needs vary from practically zero to limitless (Beauchamp and Childress 2009). The means for collective health maintenance and restoration have become an overwhelming societal commitment. The cost is covered by methods of taxation or expropriation through the government in the same fashion as other public obligations are fulfilled. The lack of any voice over the distribution of these indiscriminately and forcibly collected funds by contributors and beneficiaries amounts to an absence of representation as a serious deficiency. Many existing health care systems are or contain variants on this theme. Since demand is expected to continuously outpace the available means, a troubling question remains: who has the moral authority to decide on some members of society to be left with less fair opportunity or a smaller degree of social protection?

A partial retreat from this extreme societal mandate and its ethical dilemmas allows a novel approach. This proposal follows up on the distinction between a right to health care and a right to health, which was suggested by Beauchamp and Faden (1979). If the privilege only goes as far as a right to health, no positive obligation is created for anyone. Instead a free pursuit of any measures towards the promotion of individual health is encouraged without any undue interference. We have exchanged a positive and potentially stifling right for a negative one. This implies the difference between permitting an activity versus having to actively promote it. With this modification society must not impede a person's care for his own health, but is no longer committed to designating resources for individual wellbeing. Thus health is declared a private good, which falls under the responsibility of its owner.

There still remain two essential common good aspects to this approach. Many developing countries demonstrate that in the absence of an organized health care system citizens are at a distinct disadvantage to promote their health in view of abysmal poverty and lack of basic communal needs, in particular sanitation and fresh water. Such resources can generally be taken for granted by citizens of Western nations. Even under these favorable conditions health still has a common good element, which places a duty on society for collective social protection and fair opportunity. Besides provision of the basic infrastructure citizens can rightly expect mitigation or removal of external, universal threats to all citizens' health. Such factors could be an impending influenza epidemic or a bioterrorism assault. These circumstances are the domain of public health, which is justly covered by general tax revenues and is not the topic of the present discussion. This proposal is concerned with the numerous varieties of individually manifested diseases, which often are of unknown origin, influenced by a combination of diverse personal and environmental factors, and dependent for their mitigation or cure on a functioning health care system, which is the ultimate goal of this proposal.

A second common good aspect is the expected outcome of an effective, all inclusive health care system, specifically an optimum average health status of the entire citizenry, which is enhanced by every single act of promotion of individual health. The overall result is maximum productivity and revenue for the general benefit of all.

So far we have distanced the discussion from an a priori right to health care and place the responsibility for the active pursuit of health on each citizen with the assumption of possession of competence. The result is a multitude of citizens, who can be presumed to have the common interest of promoting their own health and are willing to invest means for this purpose. There is no reliable indicator for the vicissitudes of life, which may leave one person sick and poor and another healthy and successful. Such personal conditions may be easily reversed due to the lottery of nature. Since these experiences are common to all human beings, there is natural empathy towards fellow men. This implies a pervasive awareness of interdependence, interrelationship and community sense for a foundation of individual and societal welfare. It is noteworthy that caring 
for the poor and sick has been a principal moral guideline in Judaism, Christianity and Islam.

Modern writers, for example Gilligan (1989) have stressed the core notion of caring for and taking care of others which emanates from a strong sense of being responsible. This is directly applicable to the care for health. The author continues: "In this construction responsibility means acting responsively in relationships, and the self as moral agent, takes the initiative to gain awareness and to respond to the perception of need." The media tell us frequently about noble deeds of assistance to others in distressed situations. Money is generously contributed to causes which are perceived as good. In this context the emphasis is on the concern for health, foremost for one's own, secondly for kin, friends, neighbors, and fellow citizens. The fitting ethical principle, invoked for application here, is beneficence. Traditionally this concept has been ascribed to providers of health care. In this context it is a natural attitude and readiness to actively live the human interrelationship and bonding between fellow men and to be conscious of others' needs. The good Samaritan of biblical times illustrates this fundamental orientation and promptly responds to an unspoken cry for help (The British Foreign Bible Society 1898).

The concept of autonomy is firmly established in the patient provider relationship, and has in essence terminated the traditional medical paternalism. The term contains another far reaching meaning, which will be explored here for its usefulness in a new approach to health care. In the commonly applied sense autonomy safeguards the patient's power over his own body, forbidding any invasive intervention without specific consent. In this discussion the concept is expanded to include an implicit authority over the means, which are necessary to purchase availability of health care services and their actual administration.

The Good Samaritan serves as an original example of an independent, autonomous agent, who on his own appraised the desperate situation of a fellow man. His naturally embedded ethical quality of empathy and beneficence guided him to recognize that the victim needed assistance and as a fellow human deserved support to restore him to function or at least to alleviate his suffering. The Good Samaritan decided to allocate appropriate means of his own without any duress or external pressure for the purpose of providing the modern equivalent of health care to the injured man. In this particular instance the means consisted of his own animal for transportation and his own money to purchase the care giver duties of an inn keeper. We were not informed about the type of specific injury the victim had suffered. The Good Samaritan might have secured the services of a physician or a hospital, if such action had been indicated.
We utilize the newly modified ethical principles of beneficence and autonomy to construct the organization of a citizen carried, closed system of health care. Solidarity in the vulnerability to diseases and impairments of health fosters a common interest in the availability of preventive, mitigating or curative interventions. The presumed attitude of beneficence in the majority of persons leads naturally to a willingness or expectation to contribute towards this purpose. It follows that employers are members in a health care cooperative as individuals. Contributions from companies, government agencies or other third parties, which are traditionally solicited in current systems, are no longer compatible with invoking beneficence as the obliging ethical principle in the human interrelationship of caring.

Continuous flux is anticipated from a state as beneficiary to an additional role of contributor, as children grow up and become independent. In reverse formerly successful persons, who qualified as contributors, may fail and become dependent due to bad luck or the lottery of life.

In contrast to the often casual charitable giving for health care in the past, a modern system of reliable distribution of the financial burden is proposed. If the lottery of life or good luck lets one person remain healthy and become wealthy, it is morally justifiable to expect a greater contribution towards the care for other less fortunate fellow humans. The American philosopher John Rawls (1971) tolerates inequality in position and fortune, as long as it benefits the least advantaged. This point emphasizes the weight of beneficence as a fundamental ethical argument in favor of progressive taxation. All monetary contributions, small and large, which are collected from all participants in accordance to their means flow into a common resource pool, comparable to an insurance fund. In contrast to the current system these reserves are owned by the contributors and the potential beneficiaries. Frequently investment in the restoration of any health impairment by far exceeds individually available means. In addition to the postulated quality of universal beneficence contributors are motivated by the relative safety, which pooling of resources affords. The emphasis is placed on 'relative', since there is no a priori testimony that all possibly beneficial health care interventions must be provided to each and all members of society at any time. Such postulate clearly belongs into the realm of utopia.

An expanded meaning of autonomy is invoked here to assign a role in self-government to all members of this newly formed interest group. A multitude of autonomous agents with a common interest unites into a self-governing cooperative. Its purpose is collective decision making by a democratic process for redistribution of the accumulated resources for exclusive benefit of the members, in this case their health care needs. 


\section{Proposal for organization of a new health care system}

Beneficence is translated into regular monetary contributions for one's own and others' health benefits. This benevolent trait is projected into a multitude of members of society and beneficence as a universally postulated attitude is ready to be channeled into an effective and efficient way to organize a functioning health care system. The power of an independent, autonomous agent is instilled unto each competent modern member of society and envisioned to cooperate in collective action to establish and maintain a means responsive health care system. In other words newly empowered health care consumers do not only exclusively contribute financially to the operation of a health care system, but additionally control the allocation of all resources for their own benefit. In their positions as individual members of society they are participants in a cooperative health care system with simultaneous roles of contributors and beneficiaries. Thus every member of society as a prospective patient assumes new dual roles except a minority of individuals, who on the grounds of their specific underlying chronic disability remain without any means, are exempt from the expectation to contribute, but nevertheless participate as beneficiaries.

The size of the proportionate contributions from members is guided by the available data on current annual health care expenditures per capita for any existing system. Members of the new cooperative decide on whether they can afford or wish to continue the same collective investment into their health and the treatment for any impairments. Detailed estimates offer choices of a range of percentages from every income necessary to reach either the same, higher or lower total annual resource pools to be redistributed for health care. The accounting system will be distinctly separate from the general government budget, to conform to the postulate of self-governance.

The overall magnitude of the health care resources may fluctuate from year to year corresponding to the economic situation and determines the equal access options for all beneficiaries. The advantage of such closed system is its relative resistance to a financial crisis. Even if the minority of wealthy patrons is reduced and the income of the majority of citizens is generally depressed, the new health care system will still be able to provide equal care to all, though at a mere basic level with sharply diminished allowances for high cost interventions.

It is noteworthy that for example German health care authorities have dealt with such an eventuality by publishing a ranking of medical services according to urgency of need. The Central Ethics Commission of the Federal Republic distinguishes between four stages of prioritizing need for medical services in a position paper. These range between measures to protect life as the most compelling goal and interventions for mere improvement of function as the least important in this context (Zentrale Ethikkommission 2007a).

A historic experiment was undertaken in the US State of Oregon with its Basic Health Services Act of 1989. By a democratic process a list of priorities for medical interventions was constructed which were to be delivered according to their ranking in urgency of need depending on the availability of public funds. The plan was deeply flawed, since the uninsured as potential beneficiaries were not given any voice (Nelson and Drought 1992). This omission is effectively corrected by the newly assigned role of autonomous decision making for all competent participants over allocations. On the income side they collectively decide on the affordable intake for the health care fund. By this action they commit themselves to a self imposed financial burden according to their means. On the service side they decide on the dimensions of health care interventions on the basis of and restrained by the availability of funds and thus on the affordability of services.

This correlation is an effective cost control mechanism. If a higher level of services is advocated and desired, a commitment to higher contributions is required and is approved or denied by a democratic process. A just formula for implementation or rejection amounts to an all or nothing principle to ensure nondiscrimination. Its practical effect either ensures sufficient contributions from everyone to make any given intervention available to all according to statistically calculated potential demand and cost or no member can be granted this particular benefit.

The newly empowered members of a cooperative or their representatives negotiate with the provider conglomerate over the conditions of health care delivery.

Participants in their new role of managers of their own health will count on their physicians' special knowledge on individual risk profiles and targeted prevention planning. Downing (2009) discussed the promise of personalized medicine to reduce long term disability costs and postulated new participatory roles for consumers, which is the central theme of this proposal.

Government authority is needed to safeguard transparency, collection of contributions, a strictly designated, specific health care administration, enforcement of democratic processes, quality assurance of the provider system, a monitoring function, and an arbitration role for disputes. Any transfer of health care funds to any other purpose at the government level is prohibited.

\section{Discussion of potential weaknesses and objections}

The charge for justice is seemingly opposite on the input and the output sides for the purpose of financial balance. 
Because of the given uneven economic success the intake of contributions ranges widely between zeros in case of disabled persons to a considerable size from a wealthy member. On the service side, however, a fair opportunity rule, even in a restricted application, considering its ultimate futility, demands equal access to health care for all and potentially uneven investment according to individual need. This apparent contradiction between gross discrimination against a minority of wealthy citizens as co-contributors and a universal mandate against discriminatory practices on behalf of all beneficiaries is resolved on ethical grounds.

The difference between contributions is potentially huge in absolute terms, but is less stinging in relative proportions. A small tax on a small income is expected to be as painful as a large expropriation from a large income. The justifying argument rests solely on an appeal to the obliging role model of the Good Samaritan. The postulate that financing of health care be a designated and fully transparent system is expected to enhance the reference to the biblical story. The effect of the good is pervasive, identifiable and clearly visible. Should for whatever reason a part of the highest incomes is exempted from the proportionate deduction for health care, the proposed system will not necessarily collapse, however, the good that could be done to scores of beneficiaries will be significantly reduced. The cause of such deprivation would be known publicly as a consequence of the transparency of the system.

Lastly any refusal to participate and contribute according to means will have a similar cumulative effect. If the ethical argument is not convincing enough for objecting would-be non-participants, who insist on gambling with their health, the taxing authority of the government has to enforce income deductions for health care, and of necessity overrule the right to property in favor of a common good. On the other hand the same right must be allowed to prevail in a free society, if wealthy citizens were to invest additional resources into their own or their kin's promotion of health, after they have fulfilled their sizable obligation to the health care cooperative. An attempt at a ban of medical services outside the proposed health care system would inevitably encourage undesirable black market activity.

The question may be raised whether the 'average' citizen is ready for the proposed in depth involvement in a serious issue like health care. Goodman and Musgrave (1990) advocated for empowering patients, as this proposal does. These authors responded to the claim that "individuals are not smart enough to make wise decisions" with the pointed question: "If that argument is persuasive in health care, why isn't it equally persuasive in any other walk of life?" Who could reasonably be more interested in one's health and its promotion than its owner. This presumed weakness is eventually transformed into its greatest strength, namely effective cost control. Requesting beneficiaries to be financial contributors according to means will result in critically minded consumers, who are aware of the actual cost of health care, which is not encouraged in the current systems. Furthermore the correlation between each individual's choices of preventive actions and decreasing costs becomes a personal experience. Health care consumers will learn that indulging lifestyles are directly related to increased vulnerability to diseases and pathological aging and subsequent higher expenditures. Therefore motivation will increase to adopt practices in the care for their health, which will make the prediction true on a large scale that major scourges of modern civilization are preventable, namely cardiovascular disease, stroke (Pearson et al. 2002) and many forms of cancer (World Cancer Research Fund/American Institute for Cancer Research 2007).

A controversial issue is the possibility of forfeiting access to health care. Increased transparency and the close relationship between contributors and beneficiaries may readily reveal seemingly avoidable health care costs, accrued by consumers' poor personal choices, and possibly exert constructive social pressure. Should the new proposal adopt a method of correlating reimbursement schedules for presumably self-inflicted health impairments according to degrees of contributory negligence and reduce or deny coverage? A procedural solution offers itself most readily. As long as an absolutely reliable detailed analysis of causative factors is not feasible, consequences of obesity, drug and alcohol addiction or any other self indulging vices will lastly culminate in personal tragedy, suffering and deprivation and should fall under the provision of the postulated moral care obligation. It is noteworthy that German ethical guidelines have expressed a similar sentiment (Zentrale Ethikkommission 2007b).

A contributor, who objects to specific health care interventions for religious or moral reasons, may be outvoted, and not succeed to prevent application of his funds to the detested action. However, he may avail himself of democratic means and campaign to persuade his co-contributors to adopt his position.

The most intriguing characteristic of the new system is its reduction to the simple, naturally presumed basic human bond of empathy, as was so convincingly shown by the Good Samaritan. Its greatest strength is also its greatest deficiency, as it implies an 'ought to', but not a 'must'. This weakness is overcome by the authority invested in the government, where needed.

\section{Shift from the present to the new system}

Information through education is the key to creating a new attitude. The perception of health care as an entitlement 
and a right is the main barrier to a change of a position of empowerment and decision making ability for a new type of consumer. One modern advantage is the abundance of detailed information on health and health care, which is easily accessible to many via the internet. It is very easy for anyone to collect expanded knowledge on his or her diagnoses, treating physician's statements, prognosis and options for the future. What is much less in the foreground is a discussion about financial aspects of health care, specifically any given intervention. The present system does not lend itself to a frank discussion of the cost involved in any medical service.

A first step towards close engagement of the consumer as the future sole contributor in the new system is a disclosure mandate for specific costs of all procedures and medical/nursing interventions. A second step within the context of an educational campaign is regular publication of average per capita expenditures on health care at the national level and an honest report on the success of efforts to contain them. These figures serve as guidelines for an estimate of the total revenue, which will have to be collected from all prospective contributors in the new system according to their individual means. Economically disadvantaged persons, namely the poor, chronically ill and disabled and children are enrolled as beneficiaries and are naturally exempt form any monetary obligation. Great emphasis is placed on potential cost savings through adherence to preventive measures and a healthy lifestyle. This correlation and the idea of self-control over health outcomes are fully integrated in school curricula corresponding to students' level of understanding.

The administrative and organizational framework of institutions for health care of the current system can be maintained, since the day to day operations of claim handling must continue. Directing and decision making responsibilities will be gradually turned over to elected representatives of all enrolled contributors and beneficiaries, advancing from limited pilot studies to universal implementation.

Third party contributions from general tax revenues and employers, where applicable, may be gradually phased out, while the financial burden is slowly shifted to the citizenry according to assessments of individual means. Representative voting is introduced to respond to the fundamental questions of overall investment on the intake side and specific services to be reimbursed. Standardization of procedures throughout the new system will increase efficiency and effectiveness.

Finally a public referendum may be presented with a clear choice for voters. The present system entails continued cost escalation, indiscriminate expropriation, undue economic burden on employers and anonymously imposed restrictions. The new system is a citizen carried and self- governed cooperative; its household is strictly separated from the government, which is unencumbered by a commitment to a right to health care.

\section{Conclusion}

The perception of a right to health care has unduly led to an entitlement mentality and uncontrollable cost escalation. A retreat to personal responsibility interrupts the cycle of growing supply and increasing demand by introducing a criterion of collective affordability. A reflection on the historic charitable element places the responsibility for health and health care on each individual competent member of society. Advocacy for a right to health care is ethically justifiable, if its fulfillment is based and at the same time limited in its dimension by beneficent, autonomous agents, who transition through roles of contributors and beneficiaries. The need for health care persists, independent of its eventual source of funding. Current systems obscure the origin of financing by mostly indirect and indiscriminate taxation, when it ought to be an expression of a traditional fundamental interpersonal human relationship of caring.

Open Access This article is distributed under the terms of the Creative Commons Attribution Noncommercial License which permits any noncommercial use, distribution, and reproduction in any medium, provided the original author(s) and source are credited.

\section{References}

Anderson, G.F., et al. 2000. Health spending and outcomes: trends in OECD countries, 1960-1998. Health Affairs 19(3): 151-157.

Beauchamp, T.L., and J.F. Childress. 2009. Principles of Biomedical Ethics, 261. New York: Oxford University Press.

Beauchamp, T.L., and R.R. Faden. 1979. The right to health and the right to health care. Journal of Medicine and Philosophy 4(2): $118-131$.

Boards of Trustees for Medicare. 2009 (May). Annual report, Centers for Medicare and Medicaid Services, U. S. Department of Health and Human Services.

Denier, Y. 2008. Mind the gap! Three approaches to scarcity in health care. Medicine, Health Care and Philosophy 11(1): 73-87.

Downing, G.J. 2009. Key aspects of health system change on the path to personalized medicine. Translational Research 154: 272-276.

Gilligan, Carol. 1989. Mapping the moral domain, new images of self in relationships. Cross Currents 39(1): 50-63.

Goodman, J.C., and G.L. Musgrave. 1990. Patient power: solving America's health care crisis. Washington, DC: Cato Institute.

Kaiser Family Foundation. 2009. Snapshots, 'health care spending in the US and OECD countries'. http://kff.org/insurance/snapshot/ chcm01030oth.cfm\#back10. 4 Dec 2009.

Lenain, Patrick. 2000. 'Sante to the French health system', OECD observer, 19 October. http://www.oecdobserver.org/news/full story.php/aid/356.html. 18 Nov 2009.

Nelson, R.M., and T. Drought. 1992. Justice and the moral acceptability of rationing medical care: the Oregon experiment. Journal of Medicine and Philosophy 17(1): 97-117. 
Organization for Economic Cooperation and Development. 2009. OECD health data: statistics and indicators for 30 countries. http://stats.oecd.org/Index.aspx?DatasetCode=Health. 9 April 2010.

Pearson, T.A., et al. 2002. AHA guidelines for primary prevention of cardiovascular disease and stroke: 2002 update. Circulation 106(3): 388-391.

Rawls, John. 1971. A Theory of Justice, 302. Cambridge, MS: Cambridge University Press.

The British Foreign Bible Society (ed.). 1898. The Holy Bible, St. Luke 10, 25-37, 1044. Cambridge, UK: Cambridge University Press.
United Nations Declaration of Human Rights. 1948.

World Cancer Research Fund/American Institute for Cancer Research. 2007. Food, nutrition, physical activity, and the prevention of cancer: a global perspective. Washington, DC: AICR.

Zentrale Ethikkommission bei der Bundesaerztekammer. 2007a. Priorisierung medizinischer Leistungen in der Gesetzlichen Krankenversicherung (GKV), position paper, section 3.1.3. http://www.zentrale-ethikkommission.de.

Zentrale Ethikkommission. 2007b. Ibidem, section 3.1.2. 4 Dec 2009. 